\title{
Los perfiles de artistas de Leila Guerriero: las tramas en las versiones posibles de una vida
}

\section{Leila Guerriero's artist profiles: the plots in the possible versions of a life}

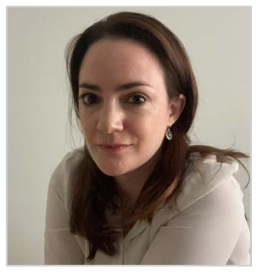

Laura Ventura. Doctora Internacional en Filología Hispánica por la Universidad Autónoma de Madrid, con una tesis calificada con Sobresaliente Cum Laude. Obtuvo la beca Carolina para realizar una maestría en la Escuela de Lexicografía de la Real Academia Española. Licenciada en Letras, por la Universidad del Salvador, en Ciencias de la Información, por la Universidad Austral, y magíster en Periodismo, por la Universidad Di Tella. Profesora de Literatura en la Universidad Carlos III de Madrid donde imparte, en el grado de Humanidades, entre otras asignaturas, Literatura Comparada y Literatura Hispanoamericana. Profesora del Máster de Lengua y Literatura Españolas Actuales en la misma universidad donde imparte las asignaturas Imágenes y representación: la representación del cuerpo e imágenes de la sexualidad y Relaciones de poder en la producción social de los discursos literarios y no literarios. Desde 2010 hasta 2014 integró la cátedra Contenidos Culturales Contemporáneos, en la Universidad Austral, a cargo por entonces de Pedro Luis Barcia. Coautora junto con Barcia de: El camino en la literatura. Viaje a través de lenguas y culturas (2013), y El túnel, los caminos subterráneos de la cultura (2020). Escribe desde más de una década en diversas secciones del diario argentino $L a$ Nación (Cultura, Espectáculos, La Nación Revista, Ideas, Exterior, etc.) y es crítica teatral.

Universidad Carlos III de Madrid, España

marventu@hum.uc3m.es

ORCID: 0000-0003-2981-1483

Recibido: 03/09/2021 - Aceptado: 21/11/2021 - En edición: 09/12/2021 - Publicado: 01/01/2022

\section{Resumen:}

El objetivo de este artículo es explorar los perfiles de artistas creados por la narradora argentina Leila Guerriero, una exponente de los autodenominados Nuevos Cronistas de Indias de América Latina. En estas piezas plasma Guerriero la voz, las contradicciones y las obsesiones de estos realizadores hispanoamericanos a través de su mirada donde se advierte la subjetividad de la cronista. Esta perspectiva es una pieza clave de la destreza narrativa de la Guerriero, a través de la cual crea estos discursos biográficos. La cronista busca y encuentra, en la interacción con sus entrevistados, y en la interpretación de sus relatos y de sus actos, a través de una aproximación hermenéutica, "tramas", en términos de Paul Ricoeur. Con ellas diseña estos perfiles o estas versiones posibles de una vida, que, en muchos casos cuestiona las versiones oficiales, y lo hace acudiendo a elementos de diversos géneros para cincelar una expresión original.

\section{Palabras clave:}

Leila Guerriero; crónica; periodismo narrativo; perfil; no ficción.
Received: 03/09/2021 - Accepted: 21/11/2021 - Early access: 09/12/2021 - Published: 01/01/2022 Abstract:

The purpose of this article is to explore the artist profiling by Argentine author Leila Guerriero, an outstanding member of the Latin American movement that calls itself the New Chroniclers of the Indies. In these texts, Guerriero captures these Hispanic American creators' voice, contradictions, and obsessions through her personal gaze, in which the author's subjectivity emerges. Perspective is a key piece in Guerriero's narrative dexterity, one that allows her to produce these biographical discourses. Using a hermeneutical approach, in her interaction with her interviewees, as well as in her interpretation of their accounts and actions, the chronicler seeks -and finds- "plots," in Paul Ricoeur's terms. With them, and resorting to tools from a wide array of genres, she designs these profiles, or possible versions of a life, that often challenge the official ones.

Keywords:

Leila Guerriero; chronicles; narrative journalism; profiling; nonfiction.

Cómo citar este artículo:

Ventura, L. (2022). Los perfiles de artistas de Leila Guerriero: las tramas en las versiones posibles de una vida. Doxa Comunicación, 34, pp. 291-305.

https://doi.org/10.31921/doxacom.n34a1463 


\section{Introducción}

La crónica en América Latina goza de salud y de protagonismo en la escena literaria hispanoamericana. Existe un contexto propicio para destacar. En primer lugar, la unión transnacional de los cronistas, autodenominados Nuevos Cronistas de Indias, a partir del encuentro celebrado en 2012, auspiciado por el Consejo Nacional para la Cultura y las Artes de México (Conaculta) y la Fundación Gabo [antes llamada Fundación Nuevo Periodismo Iberoamericano], institución diseñada e impulsada por Gabriel García Márquez (Ramírez, 2012). Entre este grupo de autores se encuentran Leila Guerriero, Juan Villoro, Alma Guillermoprieto, Alberto Salcedo Ramos, Josefina Licitra y Martín Caparrós, entre otros. En segundo lugar, el amplio circuito que la crónica ha construido para fortalecerse: instituciones, premios y publicaciones, muchas de ellas digitales, y, por lo tanto, con un acceso para un público amplio, y, también, en muchos casos, gratuito (Guerriero, 2016, p. 12). En tercer lugar, un hecho que debe destacarse: el espíritu docente y transnacional de los cronistas quienes siembran en sus alumnos modos de ver, y brindan herramientas para intentar comprender realidades complejas en países que aún buscan consolidar sus democracias o denunciar abusos del poder. La crónica latinoamericana es un amplio universo de textos de no ficción, textos construidos con las herramientas de la literatura, donde se incluyen, por ejemplo, los perfiles de Guerriero. Esta expresión vernácula ha atravesado diferentes siglos y momentos y ha sido influida o condicionada por contextos políticos, por ejemplo, la prohibición de la Inquisición española de publicar ficción, como señala Mario Vargas Llosa en "Novela primitiva y de creación en América Latina", un hecho que catalizó voces y plumas como la de Ricardo Palma (1991, p. 29). Esta expresión es previa al denominado Nuevo Periodismo estadounidense y además tiene diferencias sustanciales en circunstancias de producción, como señala Pablo Calvi (2010). Rodolfo Walsh, quien le da una vuelta de tuerca al género, un autor considerado revitalizador del género en el siglo XX, publica Operación Masacre en 1957, antes de la antología de Tom Wolfe llamada Nuevo Periodismo (1973). Walsh ha sido una inspiración para cronistas como Guerriero, quien escribe "Rodolfo Walsh, o cómo no ser el hombre cualquiera" (2008), y el prólogo de la reedición de esta novela sin ficción (Asteroide, 2018).

Fue Juan Villoro quien brindó la definición más extendida, y citada por sus pares, de la crónica, metonimia de un universo amplio que engloba el concepto de periodismo narrativo, no ficción, incluso a la "novela sin ficción", como designa a este género Jorge Carrión en el prólogo de El Interior, de Martín Caparrós (2014, p.7). El consenso de quienes estudian, leen y narran a través de estas capacidades expresivas se encuentra en el "ornitorrinco de la prosa", una metáfora que también da cuenta de su aproximación poética para narrar hechos verdaderos, ajenos a la ficción:

\footnotetext{
Si Alfonso Reyes juzgó que el ensayo era el centauro de los géneros, la crónica reclama un símbolo más complejo: el ornitorrinco de la prosa. De la novela extrae la condición subjetiva, la capacidad de narrar desde el mundo de los personajes y crear una ilusión de vida para situar al lector en el centro de los hechos; del reportaje, los datos inmodificables; del cuento, el sentido dramático en espacio corto y la sugerencia de que la realidad ocurre para contar un relato deliberado, con un final que lo justifica; de la entrevista, los diálogos; y del teatro moderno, la forma de montarlos; del teatro grecolatino, la polifonía de testigos, los parlamentos entendidos como debate: la "voz de proscenio", como la llama Wolfe, versión narrativa de la opinión pública cuyo antecedente fue el coro griego; del ensayo, la posibilidad de argumentar y conectar saberes dispersos; de la autobiografía, el tono memorioso y la reelaboración en primera persona. El catálogo de influencias puede extenderse y precisarse hasta competir con el infinito. Usado en exceso, cualquiera de esos recursos resulta letal. La crónica es un animal cuyo equilibrio biológico depende de no ser como los siete animales distintos que podría ser (Jaramillo Agudelo, 2012, p. 15).
} 
Leila Guerriero (Junín, 1967) también plasma sus reflexiones sobre el género en Zona de obras (2016), una publicación híbrida -como la crónica-, que contiene ensayos, conferencias, artículos, clases, etc. También en Frutos extraños (2006), la primera compilación de sus crónicas y perfiles publicados en distintos medios latinoamericanos, aparecen desarrolladas sus ideas estéticas y periodísticas. Guerriero es una de las referentes del género, no solo como autora, sino también como editora de una de las revistas más destacadas de periodismo narrativo: Gatopardo. Ha retratado la actividad del Equipo Argentino de Antropología Forense (crónica por la cual obtuvo el premio de la Fundación Gabo) y se ha sumergido en Las Heras, un pueblo perdido de la Patagonia para intentar comprender los motivos que inducían a que se produjera allí una ola de suicidios juveniles, Los suicidas del fin del mundo (2006). También en Una historia sencilla (2013) bucea en un torneo de malambo de gauchos del siglo XXI, en Córdoba. Su trabajo integra además dos antologías fundamentales para comprender el papel que desempeña la crónica en el escenario latinoamericano del siglo XXI: Mejor que ficción (Anagrama, 2012), editada por Jorge Carrión, y Antología de crónica latinoamericana actual, editada por Darío Jaramillo Agudelo (Alfaguara, 2012). Su último libro, Opus Gelber. Retrato de un pianista (Anagrama, 2019), es el perfil más extenso que ha realizado hasta el momento donde recorre la vida del concertista de argentino Bruno Gelber.

\section{Metodología}

En este artículo se exploran los perfiles de artistas de Guerriero, quien crea piezas literarias, no solo periodísticas vinculadas a un contexto noticiable inmediato, por ejemplo, la inminente publicación de un libro, la obtención de un premio, la inauguración de una muestra, etc. Los perfiles de Guerriero permiten al lector acercarse a estas vidas y obras gracias a las tramas que crea, construcciones que, como señala Paul Ricoeur tienen un valor que va más allá de lo literario:

¿No consideramos las vidas humanas más legibles cuando son interpretadas en función de las historias que la gente cuenta a propósito de ellas? ¿Y esas historias de vida no se hacen a su vez más inteligibles cuando se les aplican modelos narrativos -tramastomados de la historia propiamente dicha o de la ficción (drama o novela)? (1996, p. 107).

"La vida: un relato en busca de narrador", Tiempo y narración II, configuración del tiempo en el relato histórico y Sí mismo como otro, de Ricoeur, ofician como marco teórico para comprender la complejidad de la narrativa de Guerriero y de su aproximación hermenéutica hacia la vida y la obra de los distintos artistas. A través de un elemento crucial, su mirada, de su subjetividad, y de su interpretación construye en sus perfiles tramas posibles de vidas humanas. Se indagará sobre la mirada de Guerrero en sus perfiles, en primer lugar, y luego, en segundo lugar, se buscará, partiendo de la definición de Juan Villoro de crónica, señalar la utilización de diversos recursos narrativos -por ejemplo, convertirse en un personaje, secundario, pero personaje al fin- y géneros en sus perfiles. Estos últimos que emergen en sus escritos son propios del teatro, como pequeñas escenas y diálogos, o la creación de ambientes y atmósferas propias de la novela o del cuento y, de este último, con la idea de un final, y nuevamente, para regresar al concepto central de este trabajo, una trama.

Guerriero ha realizado perfiles muy diversos, no solo de artistas, la gran mayoría de ellos publicados en medios de comunicación. El corpus de este artículo está integrado por la antología Plano americano, Opus Gelber, y un perfil de María Kodama publicado en 2020 en el diario El País. 


\section{El plano y la mirada: en busca de una trama}

Guerriero en sus perfiles propone textos intimistas, en ocasiones irreverentes, con una perspectiva diferente al del periodismo tradicional: "Sean invisibles: escuchen lo que la gente tiene para decir. Y no interrumpan. Frente a una taza de té o un vaso de agua, sientan la incomodidad atragantada del silencio. Y respeten", escribe en "Arbitraria", una especie de manifiesto que abre Zona de obras (2016, p. 14). Uno de los ejemplos más nítidos, y recientes, es el de "Apuntes sobre María Kodama", publicado en el diario español El País. La viuda de Jorge Luis Borges presenta su libro de cuentos, es decir, que está abierta a las entrevistas en un contexto de promoción, pero Guerriero pauta más encuentros con ella. La cronista quiere construir un perfil, quitar la máscara que muchos personajes utilizan cuando se enfrenta a la prensa. Guerriero retrata a una mujer narcisista, que parece saber más de lo que dice en lo vinculado a la obra de Borges, de quien se desempeña como albacea, celosa en extremo de la intimidad de su propia vida y de aquello que se dice de ella, como si buscara construir un personaje y un mito, y tomar las riendas de aquella voz que se plasmará luego en el perfil. La cronista advierte esta intencionalidad:

Sus respuestas tienen siempre la forma de anécdotas que se reiteran idénticas, incluidos los comentarios y los chistes que intercala. Puesto que esas anécdotas tienen la apariencia de ser un gran-momento-confesional, suelen funcionar como hechizo que obtura la repregunta y operan como una gran maniobra de elusión (2020).

Guerriero no solo escribe o reproduce aquello que el entrevistado expresa frente a un grabador. La cronista reproduce más que el qué, el cómo, es decir, los matices de aquellos encuentros, los silencios e incomodidades y también las maniobras elusivas propias del discurso oral. Escribe también sobre los encuentros que mantiene con la viuda de Borges:

El tono es amable -aunque ante un malentendido dice exaltada: “Si te estoy diciendo que Borges ya había muerto! O no me oís o no me entendés. ¿Esto queda bien grabado?"-, pero los intentos de regresar sobre algunos temas resultan infructuosos (2020).

A través de pequeños detalles que esta cronista percibe -no ingresará en la casa de Kodama, como sí lo hace (y varias veces) con otros personajes- crea un perfil original de esta escritora en varios encuentros (Guerriero incluye la llamada un tanto hostil que mantiene con Kodama donde la increpa por la forma que tendrá luego de varias entrevistas el texto). Guerriero podría haber reproducido las declaraciones de Kodama, su estilo para vestir, algunas anécdotas (la gran mayoría ya narradas en otras entrevistas) y sus recuerdos. Sin embargo, traza un perfil psicológico, o al menos donde afloran rasgos claros de una personalidad de alguien que asegura que "la gente me quiere muchísimo" (2020), aunque no precisa quiénes son estas personas, aunque se irrite al recordar hechos ocurridos hace 25 años, aunque diga que no odia, pero el lector formule a partir de esta lectura otra interpretación posible. El título de este reportaje, "Apuntes sobre María Kodama", deja en claro que el lector se sumergirá en aquello que son apuntes, es decir, en un texto inacabado, no por parte de la cronista, sino por parte de la propia Kodama, quien interpone estos obstáculos. Se debe destacar que, a diferencia de algunos textos emblemáticos de no ficción latinoamericana, como Relato de un náufrago, donde Gabriel García Márquez reproduce la voz del marinero Luis Alejandro Velasco, la cronista interpela las voces que escucha. No se limita a reproducirlas y se aleja de la versión oficial o la que busca brindar de sí mismo el perfilado.

Ricoeur expone a lo largo de los tres volúmenes de Tiempo y narración su teoría sobre el modo en el que se construye el relato histórico y parte de lo particular para dirigirse a lo general, de lo individual a lo colectivo. Parte de la concepción de que "el yo del conocimiento de sí es el resultado de una vida examinada, contada y retomada por la reflexión aplicada a las obras, a los textos, a 
la cultura" (1995, p. 28). En este sentido, un perfil de calidad, por su indagación, su profundidad y esta mirada que examina, en el caso de Guerriero, colabora de modo involuntario con un proyecto más amplio.

Los cronistas no ocultan su presencia, su rastro en una historia, ni tampoco su mirada. Este último elemento resulta constituyente de un género y de una expresión. "Una crónica es en primer término una forma de mirar que encuentra un estilo de narrar. Una vez que se encuentra esa voz, que reproduce una particular forma de mirar, digamos que se exploran posibilidades, herramientas, recursos", sostiene María Angulo Egea (2013, p. 14). Es a través de esta mirada el modo en el que manifiesta su subjetividad. Guerriero reflexiona sobre este aspecto en una entrevista en el diario La Nación (2015):

La objetividad no existe. Cuando uno mira una realidad, lo hace con toda su carga cultural, política, social, con su pena, hasta con sus problemas de pareja. Pretender que un periodista sea completamente neutro y cuente algo como "la verdad revelada", me parece absurdo, pero eso no significa que sea deshonesto.

La objetividad no solo no es una meta, sino que resulta una entelequia del pasado. De modo reiterado así lo expresa Guerriero en las entrevistas que brinda: "El periodismo objetivo es la gran mentira del universo, todo es subjetivo", expresa Guerriero (2015). Esta cronista defiende esta aproximación narrativa y gnoseológica, en cuanto a sujeto que narra y realiza un recorte de la realidad con una mirada particular. Plano americano, la antología de perfiles de artistas hispanoamericanos, da cuenta desde el título de este foco (término periodístico, también conocido como enfoque, en referencia a una coherencia argumentativa o temática). Caparrós describe en Lacrónica a este género con una fórmula: mirada más escritura (2015, p. 65).

"La ficción y la historia pertenecen a la misma clase, por lo que se refiere a la estructura narrativa", destaca Ricoeur (2006, p. 269). Estos perfiles, piezas de no ficción, son, a través de estas tramas humanas, un ejemplo de la afirmación del filósofo. Claro está que el objetivo de Guerriero no es histórico, pero sí es documental en el sentido de que no intervienen en estos perfiles elementos de ficción, sino que se advierte una minuciosa labor de reconstrucción de aquellos episodios que los protagonistas y las voces de estos perfiles no recuerdan o desconocen, así como también de corroboración de datos. La mirada construye la trama, vertebra el relato, le busca una coherencia, un sentido.

¿Cómo es esta mirada? Precisa Patricia Poblete Alday cuando explora a la mirada en la crónica que el estilo literario, con sus múltiples recursos, es la consecuencia de la mirada.

Es importante notar que este aspecto estético es consecuencia del punto anterior -la mirada- y no es constitutivo, por sí solo, de lo "narrativo" o "literario" de este tipo de textos. Vale decir: una crónica no es "literaria" porque su autor utilice metáforas, juegue con los tiempos del relato o exhiba un dominio del lenguaje que va más allá de lo referencial; su espesor estético deriva de cierto enfoque hacia la realidad que se busca encuadrar, no hacia el texto, y ese enfoque suele estar regido por un criterio ético (2020, p. 136).

Hay en los perfiles de Guerriero hacia cada entrevistado una mirada curiosa -ni ridiculizante ni lacerante- pero a la vez poco complaciente, que no cesa de preguntar. Cada vez que una respuesta resulta poco coherente, la cronista indaga. Este procedimiento hermenéutico, esta voluntad aparece de modo explícito en algunos perfiles. La cronista encuentra y construye tramas biográficas, es decir, estos textos son mucho más que una enumeración de hechos significativos en la vida de una persona, y, en este caso, de artistas. La fotógrafa Sara Facio le espeta: “No sé de qué vamos a hablar. No soy interesante” (2013, p. 93).

"Las historias se narran, la vida se vive. De este modo, un abismo parece abrirse entre la ficción y la vida", sostiene Ricoeur (2006, p. 15) y el título del ensayo del filósofo francés -“La vida: un relato en busca de narrador”- se vuelve descriptivo a la hora de 
comprender el objetivo de la cronista. Es la construcción de una trama aquello que convierte a estos perfiles en narraciones. La trama, definida por el filósofo a partir de un enfoque aristotélico como "síntesis de lo heterogéneo", debe poseer inteligibilidad: "[...] toda historia bien narrada enseña algo; más bien, decía que la historia revela aspectos universales de la condición humana" (2006, p. 10). Guerriero crea estas tramas, no ex nihilo, como puede ocurrir con la ficción, sino que utiliza datos que se pueden verificar, por ejemplo, a través de la consulta de diversas fuentes, en relatos que resultan inteligibles.

El enfoque hermenéutico de Ricoeur se advierte en la creación de los perfiles que realiza Guerriero. La cronista no busca solo narrar, retratar, sino comprender. En términos de Hans-Robert Hauss, desarrolla "el aspecto dialógico de comprender" (Piché, 1989, p. 2), por eso sus perfiles hacen hincapié en los juegos del lenguaje, en las particularidades del intercambio entre la cronista y su interlocutor, como lo destacaba en el perfil de Kodama. También encuentra dificultades a la hora de narrar y encontrar una trama cuando se acerca a Nicanor Parra:

Llegar a la casa de la calle Lincoln, en el pueblo costero de Las Cruces, a doscientos kilómetros de Santiago de Chile, donde vive Nicanor Parra, es fácil. Lo difícil es llegar a él (2013, p. 13).

Algo similar le ocurre con Fogwill, quien le abre las puertas de su caótico departamento, y no por eso significa que acceder a él sea más sencillo. La cronista entrevista a un amigo del escritor: "El escritor es amigo de Fogwill desde hace tiempo. Y. sin embargo, no sabe, de Fogwill, nada" (2013, p. 39). En este caso no se trata de estrategias evasivas, sino de la complejidad de algunos personajes y, en este caso, el del caos en el que vivía sumergido el escritor y que Guerriero retrata en esta, parafraseando a Ricoeur, "síntesis de lo heterogéneo". También, a través de la trama, ordena y hace inteligible una vida. "Ahora me gustaría que me cuentes qué vas a hacer con todo esto", le pregunta Felisa Pinto (2013, p. 131).

Guerriero no adula a sus entrevistados y en ocasiones el lector advierte o intuye qué despierta en ella algunas respuestas determinadas. “¿De qué está hecho este hombre?” es la pregunta que admite Guerriero (2019, párr. 4), en entrevistas posteriores, y lo que la motivó a escribir el perfil más extenso que ha realizado sobre un artista: Opus Gelber, sobre el pianista argentino Bruno Gelber. La subjetividad -la simpatía e intriga- que le despierta este hombre tan excéntrico y a su vez disciplinado, se revela a partir de la mirada particular de Guerriero que destaca los elementos kitsch y ambiguos en la construcción del relato propio de su vida y de su carrera y también la gloria de este hombre que conoció los lujos y el mundo, se codea con la nobleza europea, y vive en un barrio popular de la ciudad de Buenos Aires. Durante un año Guerriero entrevista, dialoga, comparte cenas, meriendas y momentos de la vida cotidiana de un eximio músico. Existe en muchos casos un verdadero ejercicio y práctica inmersiva en la cotidianeidad de este artista, en el aspecto privado y doméstico de quien tiene una vida pública. A diferencia de Kodama, que es hermética, Gelber le presenta a la cronista a sus conocidos, la incluye en su departamento y en su círculo íntimo. En este caso, la cronista no es solo el testigo de un momento o hecho esporádico, sino que construye un vínculo con su personaje.

No hay registros grabados de cómo fueron la presentación, el intercambio de saludos, las frases casuales hasta llegar a las preguntas de la primera entrevista, pero esto es seguro: todo fue mucho más formal de lo que sería después. El humor feroz, las réplicas indóciles, el laberíntico retorno a temas inquietantes: todo eso apareció más tarde, con las semanas, con los meses (2019, p. 17).

La mirada, en otra escala, también quiere ir más allá, o, mejor dicho, adentro, acceder a una persona, conocer su modo de vincularse con los demás de comprender su pasado, sus obsesiones, sus búsquedas y dolor. No se trata solo de ingresar en su hábitat, ni mucho menos de abordar un estilo sensacionalista, sino de ingresar o de acercarse a su horizonte, en términos hermenéuticos (Piché, 1989, 
4). Para ello, la cronista necesita ser invisible. "Leila Guerriero no interfiere jamás, nunca usa a sus personajes para auto promocionarse, practica aquella invisibilidad que exigía Flaubert de los verdaderos creadores (que, como Dios, «deben estar en todas partes pero visibles en ninguna»)", escribe Mario Vargas Llosa en una reseña sobre Plano americano (2003, párr. 5) en El País.

Gelber no solo permite a la cronista el acceso a su casa/templo, le brinda el contacto de su hermana, permite que sus estrechos colaboradores dialoguen con ella. "No hubo nada que no pudiera preguntar. Tiene mucha lectura del otro. Confió en mí. Si él permite que pases a tal lado de la casa o que contactes a su familia es porque permite esa mirada", sostiene la cronista (2019, párr. 6) Guerriero intenta llegar hasta la médula de este genio. Busca ser invisible, fundirse en esa cotidianeidad, y lo logra, dado que Gelber vive en un departamento/escenario donde es siempre protagonista, donde recibe visitas que lo (ad)miran. Guerriero encuentra una trama. Si se toma la metáfora del cronista como un ser invisible, resulta un descomunal desafío para el entrevistador que irrumpe en la cotidianeidad de una persona, no ser advertido por quien sabe que será luego retratado por aquel desconocido. Interpretar para esta cronista no significa solo comprender aquello que dice el entrevistado, sino comprender cómo es la trama que construye: cuál es el personaje que quiere construir de sí mismo, cuáles son los clímax narrativos, incluso, y ya en términos de Algirdas Julius Greimas, quiénes son los actantes de su relato.

Guerriero utiliza herramientas del periodismo, escudos para evitar narrar aquello que no es verdad. Suma voces/fuentes para reconstruir la vida y la experiencia de determinado personaje. Por ejemplo, en “Quién le teme a Aurora Venturini”, entrevista no solo a la autora de Las primas, también al sobrino de la escritora y a María Laura Fernández Berro, quien fuera secretaria de Venturini durante muchos años. Guerriero desentraña las contradicciones del relato indulgente que cualquier persona comete cuando narra su propia vida, pero es en particular cuidadosa a la hora de confiar en el relato testimonial de quienes son precisamente expertos en este arte. Sigmund Freud escribe La novela familiar de los neuróticos (1909) donde se refiere al modo en el que las personas construyen su propio relato sobre su infancia y sobre sus padres (a partir de las categorías sociales y de sus diferencias, por ejemplo). Este mecanismo psíquico no implica que quien elabore este relato mienta o se aleje de la verdad, sino que es su modo de comprender su vínculo y rol en el seno familiar. Freud escribe que el neurótico "lamenta tener que compartirlo [el amor, la atención] con otros hermanitos (Dorado, 2017, p. 83).

-Yo creo que ese hermano nunca existió -dice María Laura Fernández Berro-. Ella dijo en muchas entrevistas que la madre la hizo cargo de ese chico, que lo tuvo que cuidar hasta que se murió, pero la hermana, Ofelia, dice "nunca tuvimos un hermanito así. ¿Por qué hace eso?". Se indigna (2013, p. 387).

La cronista impulsa en sus encuentros a que estos personajes examinen sus vidas, no se trata de meros comentarios o relatos aislados de hechos de su vida, sino que estos perfiles integran diversos momentos de la vida de una persona, diferentes facetas, en este caso, de un artista, que son luego narrados a través de la mirada de Guerriero.

Y cada vez que le dice Pa, vamos a ver Kung Fu Panda, quiero queso y dulce, y entonces Kohan siente que hay momentos en que es posible: que allí, bajo la superficie, están las aguas lisérgicas de su propia infancia y que, cada tanto, y gracias a Agustín, todavía puede beber de ellas. No hasta saciarse, pero beber al fin (2013, p. 196).

En Opus Gelber destaca la cronista el talento del músico, pero sin convertirse en una narradora complaciente, que elude la pregunta incómoda. Ni su sexualidad, ni sus pasiones, ni el complejo vínculo con su hermana quedan fuera del perfil. Ni su bisoñé. 
Él quiere que yo vea esto.

Quiere que yo vea todo esto.

Quiere que yo vea todo esto (2019, p. 163).

Repite el verbo ver, pero su mirada nunca es delatora, porque aquello que le interesa, la meta de su mirada, no es describir lo que tiene delante de sus ojos, lo material y tangible, sino interpretar aquello que capta sensorialmente y el lugar que ocupa: un gesto, un recuerdo, una inflexión, una conducta doméstica, incluso, como en el caso de Gelber, aquello que un entrevistado adrede dispone y exhibe teatralmente al cronista, para desafiarlo o para que lo plasme en un perfil.

"Mi relación, incluso con la gente que entrevisto, es una relación de mucha sensibilidad pero también de tener claro hasta donde llega esa relación", expresa en una entrevista que le realiza el escritor y editor español Juan Cruz Ruiz en Literatura que cuenta (2017, p. 26). No por eso abandona su estilo de reporteo, su modo de repreguntar, de formular preguntas originales que escapen al cúmulo de entrevistas que ha leído y consultado previamente sobre determinado personaje. Así advierte anécdotas reiteradas, topos discursivos, salidas airosas a frecuentes preguntas a las que se enfrenta un periodista ante un personaje particular.

En pocos perfiles predominan las respuestas extensas de los entrevistados, un hecho que no significa que el lector deje de advertir el tono, la inflexión y la reacción ante determinadas preguntas de la cronista. Es quizá en "Nada es lo que parece", el perfil a Ricardo Piglia, publicado en 2010, donde se escucha más la voz de este escritor y profesor, conferencista nato, un hombre afable que convida uvas a la cronista y donde, de modo circular, recorre este perfil una sensación de despedida (de la vida y de la obra de un intelectual).

"Una trama es una mezcla muy humana y muy poco científica de causas materiales, de fines y de casualidades", sostiene Ricoeur (2006, p. 283). En este sentido, y con vidas aún en curso, con producciones artísticas, a través de distintos problemas de acceso a sus entrevistados, que no implica solo la negativa o la evasión, sino a veces la dificultad de los propios personajes de poder narrar sus propias vidas, Guerriero confecciona vidas posibles, versiones de una vida, versiones signadas por su mirada.

\section{Los elementos del ornitorrinco}

¿Cuáles son los elementos de ficción que utiliza Guerriero para construir sus perfiles? Se señalaba previamente que Ricoeur encuentra en las tramas de las identidades narrativas elementos del "drama o de la novela" (1996, p. 107). Es por eso que se utiliza en este trabajo esta definición de Villoro de la crónica [en algunos contextos considerada sinónimo de periodismo literario o narrativo] pues se vincula, por su naturaleza híbrida y sus diversos elementos, así como por su búsqueda de la no ficción, a la propuesta del filósofo francés a la hora de comprender de qué modo se construye la historia y cómo y quiénes son sus narradores.

La crónica, como señala Juan Villoro, tiene elementos del reportaje, la información también llamada "dura”, es decir, datos estadísticos, concretos, contrastables con fuentes fidedignas, siempre aparecen en sus textos. Estos se cuelan orgánicamente en el texto, en diálogos, a través de un narrador en tercera persona, a través de una fuente, etc. Dada la rigurosidad, la documentación de esta periodista -y también docente-, el estudio de una obra y su contexto de producción, y la multiplicidad de fuentes utilizadas para buscar erradicar la ambigüedad y la mirada unívoca, sus perfiles rondan el género académico. Hay, a su vez, una posición/mirada original, una tesis que, como columna vertebral sostiene con una pregunta o foco estos perfiles. También incluso 
alguna parte de la crítica considerará estos perfiles como documentos históricos, como el mencionado perfil a Parra, poco amigo de las entrevistas, recluido del mundo intelectual y mediático. Marcela Alejandra Aguilar Guzmán estudia el concepto de lo estrafalario en varios cronistas latinoamericanos y lo vincula con el ermitaño, otro motivo de estos textos íntimamente ligados. La investigadora destaca el interés por estos personajes que aparecen en los perfiles de artistas de Leila Guerriero, por ejemplo, como en el caso de Parra.

El teatro, a través del dinamismo del diálogo, es otro de los elementos que Villoro destaca en su definición de "el ornitorrinco de la prosa". Véase el siguiente ejemplo que pareciera ser una escena de una pieza dramática.

El restaurante es un sitio familiar, con un menú que ofrece empanadas y mariscos y que él escudriña sin usar la lupa que lleva en el bolsillo (no usa gafas).

- Yo quiero una empanada de camarón, le dice a la mesera.

- Vienen dos.

Parra hace un silencio.

- Entonces nada.

- ¿Nada?

Otro silencio.

- Mire, tiene razón. Dos empanadas. Y nada más. Ya me enojé, ya (2013, p. 33).

Susana Rotker, en un libro fundamental para estudiar el género, La invención de la crónica, considera a la referencialidad como elemento distintivo de estas prosas, y, con él de la utilización de la primera persona. Guerriero se corre del lugar de personaje, elude la autobiografía, pero su voz, es, clara, no desde un plano intimista, sino profesional, como narrador que narra, valga la redundancia, y que se enfrenta a diversos desafíos en la investigación (en la experiencia) y en la escritura. En Opus Gelber aparece el siguiente pasaje donde se advierte el vínculo entre la cronista y el artista:

«No seas tan intelectual! Y después llámame para decirme cómo te fue»

Cuando obedezco, me digo a mí misma que lo hago por educación (2019, p. 253).

El hecho de ser invisible no convierte a un cronista, no al menos en el caso de Guerriero en un "narrador beige" o "aséptico", en términos de Tom Wolfe en El Nuevo Periodismo (2006, p. 30). Juan José Millás destaca la discreción de la narradora y se refiere a ella como un personaje en sí mismo dentro de la narración de no ficción.

Si se acercan ustedes al libro atendiendo a lo que dice de sí misma la voz que lo narra (que coincide con la de la autora) en vez de a los sucesos narrados, observarán que, pese a lo discreto de su presencia, la personalidad de la escritora impregna la atmósfera del libro desde el principio hasta el final. Ella, Guerriero, es la protagonista secreta, el personaje oculto que golpea en la mente del lector y del que le gustaría saber más de lo que muestra. La construcción de ese personaje velado constituye una proeza narrativa de primer orden (2019, párr. 10).

Las crónicas de Guerriero poseen también elementos de la novela, como la creación de distintas atmósferas y climas que anteceden un hecho, que puede ser o bien en el momento previo en el que la cronista conocerá al entrevistado o retazos de la memoria de la figura que retrata. La narración casi nunca es cronológica, posee analepsis que se vinculan en perspectiva pretérita con la 
personalidad (traumas, formación, penas, oportunidades, etc.) del entrevistado. Por ejemplo, así comienza "Felisa Pinto: Retrato de una dama" (2013, p. 109).

Suave es la noche.

El piso en las calles Libertad y Marcelo T. de Alvear, se abre a una plaza con árboles como capullos frescos. La anfitriona, Fanny Llambi Campbell de Ferreyra -Bebita-, acaba de regresar de un viaje en barco y da, en ese departamento que no es suyo porque desprecia respingadamente la idea de tener casas y vive entre París, Nueva York y Buenos Aires, una fiesta. Corre el año 1952, quizá 1953. Es verano. El ventanal es un paño nítido por el que entra a raudales la noche clara. Hay brisa y el zumbido lento de la ciudad se cuela en ese piso donde criaturas refinadas ríen, fuman, beben.

La mujer entra en cuadro desde la derecha. Camina como si fuera parte de la tierra, con una gracia épica, serena. Lleva una falda azul marino y una camisa de un blanco óptico, de poplín. Su rostro tiene la belleza de lo que no puede repetirse. Las líneas, que ondulan suaves en los pómulos, se transforman en la altiva arquitectura de las cejas, en la vivacidad elástica de la boca, en el carbón de los ojos. Cuando su figura atraviesa el ventanal con gracia distraída, algo, en el íntimo engranaje de esa fiesta, se detiene. Porque la mujer que acaba de rasgar la suavidad de la noche derrama, sobre los que están allí, la sensación eufórica, y a la vez triste, de estar viviendo ya un recuerdo.

Juan José Millás se refiere o ensaya una clasificación de Opus Gelber: “Lo leemos como una larga crónica (quizá como una biografía) porque así es como nos lo venden, pero lo leeríamos como una novela si hubiera aparecido bajo esa etiqueta” (2019). No se refiere el autor español a la extensión, sino a la densidad y profundidad con la que Guerriero construye a este personaje.

También hay elementos del cuento en los perfiles de Guerriero, ya que sus crónicas poseen un sentido de completitud, de coherencia, "un sentido de cancelación", término que toma Guerriero de Juan Villoro (Cruz Ruiz, 2017, p. 37). Incluso en las entrevistas o perfiles que realiza, donde no cuenta una historia precisa y específica, con progresión temporal, brinda un final, como si de un relato se tratase, por ejemplo, en el perfil del artista plástico Guillermo Kuitca, "El artista del mundo inmóvil” (2013, p. 92).

Dejar correr el tiempo. Después reír. Después pagar. Y después irse.

Y verlo irse, también, bajo la lluvia.

Un hombre sin hogar, tratando desesperadamente de volver a alguna parte.

El ensayo es propio de las crónicas, otro elemento del “ornitorrinco de la prosa”. Quizá en la prosa de Carlos Monsiváis es donde más se evidencie este elemento. Guerriero no busca aseverar, sino más bien hacerse preguntas. En el caso de los perfiles a artistas, donde se vislumbra algún rasgo del ensayo -y también se acerca así a la crítica cultural- se refiere a una obra, estética o poética en particular. Por ejemplo, sobre el cine de Lucrecia Martel escribe en el perfil de esta realizadora: "En las películas de Lucrecia Martel, la muerte y la caída son cosas que pasan fuera de cuadro. Cosas que resultan aterradoras porque, precisamente, no se ven" (2013, p. 185). También se evidencia en estos casos, con su mirada original, su exploración a una obra y contexto y el contraste de fuentes al género académico. Pero hay a su vez una posibilidad con la que no siempre cuentan los investigadores: indagar a los artistas o intelectuales que describe. Es cierto que Guerriero no propone una tesis, propone una mirada, pero aun así sostiene a esta última con argumentos y no solo con observaciones.

Es necesario regresar a Ricoeur quien destaca cómo la novela de ficción exploró con diversos recursos tramas cuyo objetivo era el de comprender más y mejor la existencia humana: “¿Cuántas convenciones, cuántos artificios son necesarios para escribir la vida, para componer por la escritura su simulacro comprensivo (2004, p. 392). El filósofo señalaba esta paradoja a través de la cual 
se acudía a la ficción para acercarse a la "vida", entendida como no ficción. El perfil, por lo tanto, por su naturaleza de no ficción, y por su utilización de elementos narrativos, como los de la novela, desmantelaría quizá esta paradoja.

Exploremos a continuación el estilo de Guerriero. Mario Vargas Llosa se refirió a este componente identitario y expresivo de esta cronista en una columna en el diario español El País, donde destaca que su prosa conjuga la precisión y la originalidad.

Cada uno de estos perfiles o retratos de músicos, escritores, fotógrafos, cineastas, pintores, cantantes, es un objeto precioso, armado y escrito con la persuasión, originalidad y elegancia de un cuento o un poema logrados. En nuestro mundo, el periodismo suele ser el reino de la espontaneidad y la imprecisión, pero el que practica Leila Guerriero es el de los mejores redactores de The New Yorker, para establecer un nivel de excelencia comparable: implica trabajo riguroso, investigación exhaustiva y un estilo de precisión matemática (2013, párr. 4).

Como señala el autor peruano, los perfiles de Guerriero combinan el rigor con el estilo (2013). Angulo Egea señala el perfil que realiza la cronista de Homero Alsina Thevenet donde se advierte esta combinación:

El comienzo de este perfil es sintomático de lo que se entiende por periodismo narrativo. Se nos aportan los datos necesarios para poder situar al personaje (uruguayo, periodista, crítico de cine), claro está, pero se nos presenta al sujeto en acción, en una escena, en un momento de su vida fundamental: se está muriendo, y nos lo cuenta en primera persona (2013: p. 18).

Juan Cruz Ruiz coloca a Guerriero en el primer lugar de las entrevistas -no dispuestas por orden alfabético- de Literatura que cuenta. Cruz explora en extensas entrevistas la retórica y el oficio de los principales exponentes del periodismo narrativo y califica de "silvestre" a Guerriero porque parece "una niña que no se acostumbra a ser la que recibe preguntas" (2017, p. 11). Cruz alude posiblemente a esta reacción o conducta durante esta entrevista, a pesar de que obtiene un extenso reportaje sobre la narradora y donde, como ella misma lo hace con sus entrevistados, logra bucear en la infancia de esta cronista, durante el Régimen Militar.

Me crié durante la dictadura, la dictadura empezó en el 76, nací en el 67, era muy pequeña. No sé si son recuerdos falsos o cosas que recuerdo con el tiempo de verdad, pero me acuerdo perfectamente de la radio porque no teníamos televisión en mi casa, del comunicado del Ejército. A saber qué decían, me acuerdo de eso y por alguna cuestión se me quedó. Se ve que había algo relacionado con el peligro, con lo siniestro, no lo sé pero me daba mucho miedo escucharlo.

Nótese que los recuerdos no siempre son fieles, certeros, Guerriero lo sabe bien, y a ellos acude, no solo para responder en este caso, sino para construir la trama de los perfiles, pues estos recuerdos dejan huellas en las psiquis.

Consulta Juan Cruz Ruiz a Guerriero cuál es o cómo definiría su propio estilo. "El estilo es como el yogur: vence cada cierta cantidad de años", le respondió (2017, p. 35). Una de las pocas impugnaciones que recibió Villoro sobre su definición de la crónica es que no menciona en aquel catálogo de género a la poesía. Uno de los sellos distintivos de las prosas, no solo de los perfiles de Guerriero, es precisamente la poesía, los versos (de otros autores, de los mismos autores que retrata o aquellos que ella escribe) que no solo le aportan musicalidad a la prosa, sino que además le brinda ritmo a los textos que pueden ser leídos como académicos (dado su fuerte valor documental), a pesar de que las citas y bibliografía no se encuentren en las notas al pie ni al final del artículo.

Los perfiles de Guerriero son textos polifónicos, mosaicos que recogen voces no solo de artistas, sino de aquellos que más conocen a determinado artista, su perfil no público, su cara más auténtica. Escribe Vargas Llosa sobre esta aproximación de Guerriero: 
[Crea una] perspectiva poliédrica de estas personas, hasta dar de ellas una impresión de totalidad, de síntesis que aprisiona todo lo que hay o hubo en ellas de sustancial. El resultado es siempre positivo, todos los entrevistados terminan por despertar la simpatía, a veces la admiración, a veces la ternura y casi siempre la solidaridad del lector (2013, párr. 6).

Hay dentro de estos perfiles de artistas un submundo diferente al de la aproximación o encuentro con el personaje a través del diálogo cuando retrata a personajes ya fallecidos, como Roberto Arlt, Idea Vilariño y Pedro Henríquez Ureña. En estos casos, la documentación es tan rigurosa como en aquellos perfiles donde sí tiene acceso al entrevistado, pero quizá sí emergen de modo más claro los testimonios de las fuentes de quienes conocieron a estos artistas. Aparece también la perspectiva de la crítica literaria, en el caso de los dos primeros artistas. Por ejemplo, para el perfil de la poetisa uruguaya, Guerriero recurre (al menos) a ocho personas u ocho entrevistas que conocieron a Vilariño: su hermano, amigas, su ex esposo. Además, reconstruye en este caso su obra y vida con todas las entrevistas que brindó, nuevamente, con un esfuerzo documental cuya mención explícita es un modo de argumentar que a través de esta perspectiva subjetiva persigue el fin de retratar del modo más fidedigno una psiquis y una poética.

Ella, que era discreta, que insistía en sostener que había concedido sólo tres antevistas a lo largo de toda su vida (contabilizaba una Mario Benedetti, en 1971; otra a Jorge Albistur, en 1994; otra a Rosario Peyrou y Pablo Rocca en 1996, pero no las que dio a María Esther Gilio, a Elena Poniatowska, a Hilia Moreira, a Ignacio Cirio), diría después y tantas veces que esa misma noche se había enamorado (2013, p. 57).

¿De qué modo emerge la voz de Vilariño? En este caso de modo más evidente que otros, a través de sus versos. Guerriero interpreta, bucea en la obra de la poetisa y acompaña su obra con una lectura biográfica. Así, selecciona versos, por ejemplo, para dar cuenta de la pasión que sentía por Juan Carlos Onetti. Los perfiles de Guerriero van más allá (o dentro) de la biografía porque las voces de estos intelectuales se advierten en estas prosas. No son relatos del pasado, sino que en estos perfiles, que proponen una mirada particular (y original), de modo cercano a un trabajo académico, emergen las voces de estos creadores que dialogan con otros artistas o fuentes. Colabora también con futuras investigaciones sobre la obra de un artista, porque para Guerriero la obra y la personalidad de un artista no son dimensiones escindidas.

\section{Conclusión}

Villoro definió a la crónica como el "ornitorrinco de la prosa", porque en ella confluyen varios géneros y subgéneros. En estos perfiles de artistas Guerriero se propone una meta mucho más honda que informar sobre un hecho específico. Estos perfiles biográficos y psicológicos buscan ingresar en la intimidad de estos creadores, desenmascararlos, deconstruir discursos fosilizados, tópicos y derrumbar tótems e ídolos. Para ello, es necesario utilizar todos los recursos periodísticos, empáticos y literarios. Previamente a la utilización de una gran variedad de elementos retóricos es la mirada la pieza clave de los perfiles. Con ella, con su subjetividad y con su interpretación construye las tramas de estos perfiles. En ocasiones hay resistencias por parte de los perfilados. Ricoeur explica que "la comprensión de sí es una interpretación" (1996, p. 107), es decir, que la cronista trabaja con dos subjetividades en simultáneo: aquella de la cual recibe el relato y la propia. Para la primera puede acudir a investigaciones o datos que busquen esclarecer cuán próxima se encuentra aquella interpretación a diversos hechos, pero asiste sin dudas a un relato, a una trama, que irá completando con otras secundarias (fuentes, testigos, documentos, etc.). 
El cronista colombiano Alberto Salcedo Ramos escribió una oda a la cronista, "Siempre Leila", contenida en Botellas de náufrago, donde se refiere al estilo de su colega: "Primero la curiosidad, después la intuición. Siempre la intuición y siempre la curiosidad" (2015, p. 350). Salcedo alude de este modo a esa orientación, ese abordaje de inmersión (intuición, intus-legere o leer dentro) de la cronista. Esta lectura se realiza en varios niveles: del propio perfilado sobre su vida, de la cronista hacia el relato del perfilado, y, finalmente, el del lector. Ricoeur propone, para disminuir el mencionado "abismo entre las historias y la vida", la acción clave del lector (2006, p.7). La trama es un proceso, antes que una estructura estática, y Guerriero nos brinda versiones posibles de una existencia que el lector completará con su acción.

Hay en la labor de Guerriero un resultado que posiblemente no sea explícitamente buscado que es el de colaborar a que el sujeto, no solo a través de la entrevista, sino de la trama que propone la cronista, (re)construya su identidad, que logre advertir cómo su identidad personal, a través de una identidad narrativa, cobra una dimensión nueva o una dimensión que no había antes considerado. Las tramas, como esquemas narrativos construidos sobre una mirada, brindan herramientas para que el lector comprenda a los personajes, y, en el caso de los perfiles de Guerriero, para que incluso los personajes se confronten a una trama posible de su propia vida, a un modo de comprenderla, a una perspectiva. Guerriero colabora de este modo a hacer legibles vidas humanas, a decodificar las tramas y los mecanismos con las que son construidas para proponer otros nuevos. En este sentido, entonces, el perfil no es apenas un subgénero del periodismo o una manifestación del periodismo narrativo, sino que cobra un valor fundamental en una sociedad que se propone la tolerancia y la empatía como valores.

\section{Agradecimientos}

Traducción al inglés de María Alejandra Goncalves Borrega.

\section{Referencias bibliográficas}

Aguilar Guzmán, M. (2018). La crónica latinoamericana actual como género y discurso. [Tesis doctoral, Pontificia Universidad Católica de Chile]. Repositorio Pontificia Universidad Católica de Chile. https://repositorio.uc.cl/handle/11534/21991

Angulo Egea, M. (eda.) (2013). Crónica y mirada: Aproximaciones al periodismo narrativo. Libros del K.O.

Calvi, P. (2010). Latin America's Own «New Journalism». Literary Journalism Studies, (2), 63-84. https://ialjs.org/wp-content/ uploads/2014/12/065-086-LJS_v2n2.pdf

Caparrós, M. (2014). El Interior. Malpaso.

Caparrós, M. (2015). Lacrónica. Círculo de Tiza.

Carrión, J. (Ed.) (2012). Mejor que ficción. Crónicas ejemplares. Anagrama.

Cruz Ruiz, J. (2017). Literatura que cuenta. Adriana Hidalgo.

Dorado, J. (9-11 de agosto de 2007). El complejo fraterno: de la familia a la segregación. [Comunicación en congreso]. XIV Jornadas de Investigación y Tercer Encuentro de Investigadores en Psicología del Mercosur, Facultad de Psicología, Universidad de Buenos Aires, Buenos Aires. https://www.aacademica.org/000-073/507 
Guerriero, L. (31 de octubre de 2008). Rodolfo Walsh, o cómo no ser el hombre cualquiera. El País. https://elpais.com/diario/2008/11/01/babelia/1225499960_850215.html

Guerriero, L. (18 de febrero de 2012). La verdad y el estilo. El País. https://elpais.com/cultura/2012/02/15/actualidad/1329307919_560267.html

Guerriero, L. (2013). El periodismo objetivo es la gran mentira del universo. Jotdown. https://www.jotdown.es/2013/11/ lei\%C2\%ADla-gue\%C2\%ADrrie\%C2\%ADro-el-periodismo-objetivo-es-la-gran-mentira-del-universo-todo-es-subjetivo/

Guerriero, L. (2013). Plano americano. Universidad Diego Portales.

Guerriero, L. (2016). Zona de obras. Anagrama.

Guerriero, L. (2019). Opus Gelber. Retrato de un pianista. Anagrama.

Guerriero, L. (27 de marzo de 2020). Apuntes sobre María Kodama. El País. https://elpais.com/cultura/2020/03/25/babelia/1585141168_415434.html

Jaramillo Agudelo, D. (Ed.) (2012). Antología de crónica latinoamericana actual. Alfaguara.

Millás, J. (22 de marzo de 2019). El personaje oculto. El País. https://elpais.com/cultura/2019/03/20/babelia/1553103615_875787.html

Piché, C. (1989). Experiencia estética y hermenéutica literaria. Ideas y Valores, 38, (81), 3-16. https://revistas.unal.edu.co/index. $\mathrm{php} /$ idval/issue/view/2051

Poblete Alday, P. (2020). Crónica narrativa contemporánea: enfoques, deslindes y desafíos metodológicos. Literatura Mexicana, (31), 133-153.

Ramírez, S. (3 de noviembre de 2012). Los nuevos cronistas de Indias. La Nación. https://www.lanacion.com.ar/opinion/ los-nuevos-cronistas-de-indias-nid1523193/

Ricoeur, P. (1995a). Tiempo y narración I. Configuración del tiempo en el relato histórico. Siglo XXI Editores.

Ricoeur, P. (1995b). Tiempo y narración II. Configuración del tiempo en el relato de ficción. Siglo XXI Editores.

Ricoeur, P. (1996). Sí mismo como otro. Siglo XXI Editores.

Ricoeur, P. (2013). La vida: un relato en busca de narrador. Ágora, Papeles de filosofía, (25), 9-22. https://minerva.usc.es/xmlui/ bitstream/handle/10347/1316/Ricoeur.pdf?sequence=1

Rotker, S. (2005). La invención de la crónica. Fondo de Cultura Económica.

Salcedo Ramos, A. (2015). Botellas de náufrago. Luna.

Vargas Llosa, M. (1991). Novela primitiva y de creación en América Latina. En N. Klahn y W. H. Corral (Eds.), Los novelistas como críticos (29-36). Fondo de Cultura Económica. 
Vargas Llosa, M. (18 de mayo de 2013) Periodismo y creación: Plano americano. El País. https://elpais.com/elpais/2013/05/16/ opinion/1368714188_384998.html

Ventura, L. (11 de enero de 2016). El rol del periodismo es entender, incluso cuando duela, La Nación. https://www.lanacion. com.ar/cultura/leila-guerreiro-el-rol-del-periodismo-es-entender-incluso-cuando-duela-nid1861107/

Ventura, L. (20 de abril de 2019). Leila Guerriero: No había manera de escribir este libro sin mi propia voz. La Nación. https:// www.lanacion.com.ar/cultura/leila-guerriero-aparezco-todo-el-tiempo-pero-no-habia-manera-de-escribir-este-libro-sin-mipropia-voz-nid2239916/

Villoro, J. (2005). Safari accidental. Planeta. 
